\title{
Problemas comuns da amamentação
}

\author{
Cristina Gouveia, ${ }^{*}$ Adelaide Órfão**
}

\section{RESUMO}

Aborda-se de forma sucinta situações comuns do lactente que podem ter impacto na lactação (hipoglicémia e icterícia do lactente, crescimento, desidratação hipernatrémica, entre outros) e em que a intervenção para a sua resolução deve ser pensada de forma a proteger e a apoiar a amamentação.

Muitas situações podem ser prevenidas pelo contacto pele a pele após o parto e o início precoce da amamentação, seguido de um aleitamento sem restrições na duração, nos intervalos das mamadas ou no acesso a uma ou duas mamas em cada refeição. As lactantes devem ainda reconhecer e oferecer a mama em resposta aos sinais precoces de fome do bebé e não ao choro, que é um sinal tardio.

Situações frequentes nos primeiros dias de vida tinham a sua avaliação inicial no internamento pós-parto, onde a mãe obtinha o apoio necessário. Actualmente, a desejável precocidade das altas após o parto desloca para o ambulatório a sua ocorrência, como por exemplo a «subida de leite», tornando fundamental a boa articulação entre os cuidados hospitalares e primários para o eficaz apoio à mãe.

Alguns dos procedimentos comuns como a suplementação com leite artificial antes de observar a mamada, não são ainda pensados tendo em conta a promoção e manutenção da lactação e podem condicionar a sua evolução.

Pesar semanalmente por rotina sem estabelecer um plano eficaz para a progressão ponderal pode minar a confiança da mãe como lactante.

Palavras-Chave: Lactação; Amamentação; Hipoglicémia do Recém-nascido; Problemas Comuns.

\section{INTRODUÇÃO}

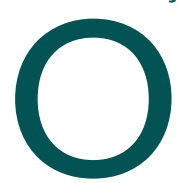

desejável regresso precoce ao domicílio após o parto implica uma boa articulação entre os dois níveis de cuidados. Ocorrendo habitualmente às 48h/72h, a «subida de leite» pode representar para as mães uma dificuldade capaz de condicionar a lactação.

Se o apoio à sua resolução for inexistente ou ineficaz pode evoluir de forma significativa para o abandono da amamentação. ${ }^{1}$ Para fazer face a este problema e contribuir para o aumento das taxas de iniciação e manutenção do aleitamento, propõe-se uma consulta/visitação domiciliária entre o $3^{\circ}$ e o $5^{\circ}$ dia de vida para avaliação da criança/mãe e da amamentação. ${ }^{1,2}$ Apresenta-se, de forma sucinta, uma abordagem de vários problemas que, ao surgirem nos primeiros dias ou durante a lactação, podem condicionar a sua evolução.

*Pediatra,Consultora de lactação IBCLC.

Administração Regional de Saúde do Algarve

**EESMO, Consultora de Lactação IBCLC.

Direcção-Geral de Saúde.

\section{HIPOGLICÉMIA DO RECÉM-NASCIDO}

Durante a gestação, o nível de glicémia do feto é mantido estável através do aporte contínuo da placenta, mas na adaptação à vida extra-uterina regista-se um declínio fisiológico com recuperação (independente da ingesta) entre a $2^{\mathrm{a}}-4^{\mathrm{a}}$ hora de vida. . $^{3-5}$

Na sua adaptação metabólica, o recém-nascido (RN) inclui o uso de lactato e corpos cetónicos como substrato energético alternativo, resposta que fica comprometida pela ingestão de leite artificial. O recém-nascido amamentado em exclusivo tem maior capacidade de produção de corpos cetónicos (em relação ao RN sob alimentação artificial) mantendo-se assintomático com níveis inferiores de glicémia. ${ }^{3,4}$

A hipoglicémia associa-se ao risco de lesão neurológica, mas o valor que a define não é consensual ( 30 a 50 $\mathrm{mg} / \mathrm{dl}$ ) e é função de vários factores: idade do bebé, tipo de alimentação, sintomatologia e patologia associada. ${ }^{4,6}$ Entre nós, é corrente o limite inferior de $40 \mathrm{mg}$ / /dl. O risco de hipoglicémia é maior no prematuro, no RN leve para a idade gestacional, e/ ou com restrição ao 
crescimento intra-uterino, trabalho de parto prolongado, jejum prolongado, filho de mãe diabética e se coexistir doença ou hipotermia. ${ }^{3,5}$

A sintomatologia não é específica e a sua gravidade é variável, podendo observar-se: sucção débil, recusa alimentar, irritabilidade, letargia, hipotonia, coma, apneia, cianose, taquipneia, respiração irregular, tremores, mioclonias, convulsões e hipotermia.

O tratamento da hipoglicémia sintomática é sempre endovenoso para a rápida normalização da glicémia. ${ }^{4-6}$

O início precoce da amamentação seguido de mamadas frequentes, cerca de 10 a 12 vezes ao dia, durante os primeiros dias de vida, em horário livre e em resposta aos sinais precoces de fome, previnem a hipoglicémia no RN saudável e diminuem a sua incidência em situação de risco.

O rastreio de glicémia, por rotina, não é recomendado no RN/lactente de termo saudável e assintomático., ${ }^{3,47}$

\section{CRESCIMENTO DO LACTENTE NAS PRIMEIRAS SEMANAS}

Após o nascimento, a excreção do excesso de líquido extra-vascular e a ingestão de pequenos volumes de colostro justificam a perda ponderal característica dos primeiros dias de vida.

Nos primeiros dias após o nascimento pode registar-se perda de $10 \%$ do peso de nascimento ${ }^{7,8}$ (raramente até $14 \%$ se o peso de nascimento for elevado e houve retenção de líquidos). ${ }^{9}$ Quando a mãe se sente confiante, identifica e responde aos sinais precoces de fome do RN pronto a mamar (movimentos de busca e de mastigação, mover e chupar os punhos, emissão de sons suaves ou irrequietude) oferecendo-lhe frequentemente a mama, a perda de peso é em geral inferior a 7\%.7, ${ }^{7,10}$

Habitualmente ao $2^{\circ}-3^{\circ}$ dia ocorre a "subida de leite», as características do leite alteram-se estando disponível um maior volume, uma maior percentagem de lípidos e um maior aporte calórico, a que corresponderá um ganho ponderal diário a partir do $4^{\circ}-5^{\circ}$ dia (em média 20-30 g/dia durante o $1^{\circ}$ mês de vida). $\mathrm{O} R \mathrm{RN}$ deve igualar o peso de nascimento até à $2^{\text {a }}$ semana de vida. ${ }^{8-10}$

São consensuais como factores facilitadores do início da amamentação, o contacto pele a pele ininterrupto e o início da amamentação na $1^{\text {a }}$ hora de vida, seguindo-se mamadas frequentes, em horário livre, sem restrições na duração, nos intervalos, ou no acesso a uma ou duas mamas em cada refeição.

No lactente amamentado há uma grande variabilidade no intervalo entre as mamadas e no volume de leite ingerido por refeição, mas não no volume ingerido diariamente. Esta situação é pouco reconhecida pelos pais e pelos profissionais habituados a prescrições de leite artificial e inseridos numa cultura em que as taxas de aleitamento são baixas.

O choro é já um sinal tardio de fome e nem todos os bebés choram após a manifestação dos sinais precoces de fome, alguns adormecem de novo falhando refeições, com repercussão no seu peso.

\section{PERDA PONDERAL EXCESSIVA NO PERÍODO NEONATAL E/OU ATRASO NO GANHO PONDERAL}

Nos primeiros dias e/ou em bebés que não estão a progredir bem de peso, são sonolentos, de baixo peso, ou prematuros, está recomendada a interrupção do sono prolongado (superior a quatro horas) para lhe oferecer a mama.

O RN deve ser observado entre o $3^{\circ}$ e o $5^{\circ}$ dia de vida $^{1,2,11}$ para avaliação da amamentação, pesagem e cálculo da percentagem de peso perdido, caso esta seja excessiva $(>7 \%)$, deve aumentar-se o número de refeições ao dia (10-12) e oferecer suplemento de leite materno, preferencialmente por copo, no final das mamadas. Pode ainda ser necessário melhorar a pega e/ou a posição da mãe e do filho, para uma transferência mais eficaz.

O registo do peso pode ser diário, ou a cada $48 \mathrm{~h}$, até que se comece a obter um ganho ponderal constante.

São de evitar a pesagem por rotina, o rastreio de glicémia em bebés assintomáticos, a introdução de suplementos de leite artificial sem plena justificação, procedimentos que podem interferir com a lactação, pois podem diminuir a confiança da mãe na capacidade de alimentar o seu filho. Salienta-se ainda o recurso excessivo à chupeta e tetina, cujo uso em bebés amamentados se associa a dificuldades na pega e à diminuição do período de lactação.

É expectável que o RN que perdeu peso após o $3^{\circ}-5^{\circ}$ dia de vida ou que teve uma perda ponderal excessiva, atinja o seu peso de nascimento após o $14^{\circ}$ dia de vida apesar de instituídas as medidas correctas, é importante reforçar a vigilância e fomentar as competências maternas na gestão da amamentação. 


\section{DESIDRATAÇÃO HIPERNATRÉMICA}

A desidratação hipernatrémica nos bebés amamentados surge por uma inadequada ingesta. A manutenção das perdas insensíveis não compensadas pela ingesta leva essencialmente à perda de água, aumentando a concentração de electrólitos no meio intravascular. $\mathrm{Na}$ tentativa de manter o equilíbrio osmótico há transferência da água intracelular para o meio extracelular.

A sintomatologia resulta do grau de desidratação (avaliado pela perda de peso) e do sofrimento celular provocado pela desidratação celular. Além da perda de peso são de valorizar principalmente os sinais neurológicos: letargia, irritabilidade, convulsões, hipertonia muscular, hiperreflexia, além de sede intensa, mucosas secas (língua seca), pele acinzentada e empastada e agravamento da icterícia. Na desidratação hipernatrémica, a hipovolémia e o choque são tardios e correspondem à desidratação grave. ${ }^{12}$

Os pais podem não se aperceber de que a criança não mama o suficiente, sobretudo se é o primeiro filho, se não chora ou, dorme muito, sinais que são muitas vezes interpretados como de saciedade. Estas crianças podem atingir níveis de desidratação e desnutrição graves.

O tratamento implica a hidratação endovenosa lenta, mantendo-se o aleitamento materno, à mama ou por copo.

A prevenção da perda de peso excessiva e da desidratação hipernatrémica está intimamente relacionada com o início precoce da amamentação, a monitorização e observação da mamada, assegurando que o processo de lactação tem uma normal evolução. Deve ser dada especial atenção quando há dificuldades na adaptação do bebé à mama e às mães que têm uma «subida de leite» tardia.

\section{ICTERÍCIA NO RECÉM-NASCIDO}

No RN de termo saudável podemos considerar a icterícia de início precoce (fisiológica) e a de início tardio (do leite materno). ${ }^{13,14}$

\section{Icterícia fisiológica}

Nos primeiros dias de vida ocorre destruição de parte da massa eritrocitária com consequente descida do hematócrito de valores de $48-69 \%$ para cerca de $45 \%$ no final da $1^{\text {a }}$ semana. A destruição da hemoglobina leva à formação de bilirrubina, cuja forma não conjugada é lipossolúvel e deposita-se na pele.

A icterícia fisiológica surge em $60 \%$ dos recém-nascidos de termo e em $80 \%$ dos prematuros e deve-se à elevação da bilirrubina não conjugada. A icterícia torna-se visível no $2^{\circ}$ ou $3^{\circ}$ dia, com pico sérico entre o $2^{\circ}$ e o $4^{\circ}$ dia. Os níveis de bilirrubina decrescem então progressivamente deixando a icterícia de ser visível entre o $10^{\circ}$ e o $14^{\circ}$ dia de vida. Os recém-nascidos prematuros têm valores semelhantes mas atingem o pico sérico entre o $4^{\circ}$ e o $7^{\circ}$ dia, deixando a icterícia de ser visível após o $10^{\circ}$ dia. ${ }^{15}$

A deposição do pigmento é cefalo-caudal, visível inicialmente nas escleróticas e face, podendo progredir até aos membros inferiores de acordo com a magnitude do nível sérico. Cerca de 6 a 7\% dos RN atingem valores máximos de 12,9 mg/dL e $3 \%$ de RN apresentam hiperbilirrubinémia não conjugada superior a $15 \mathrm{mg} / \mathrm{dL} \cdot{ }^{15}$

O mecónio contém cerca de $1 \mathrm{mg} / \mathrm{dl}$ de bilirrubina conjugada. Em situações de atraso na sua eliminação o pigmento sofre a acção da glucuronidase intestinal e reentra na corrente sanguínea (recirculação enterohepática), contribuindo para agravar os níveis de bilirrubina não conjugada e, consequentemente, de icterícia.

Constituem factores de risco para hiperbilirrubinémia: origem asiática; altitude; história de; irmão com icterícia fisiológica; diabetes materna; sindrome de Down; sexo masculino; indução trabalho parto com oxitocina; prematuridade; cefalohematoma; policitémia; vitamina K; atraso na eliminação de mecónio; amamentação não eficaz; perda excessiva de peso; (desidratação e baixa ingesta calórica).

A icterícia fisiológica é mais frequente nos RN amamentados, ${ }^{14}$ sendo que a icterícia moderada (bilirrubina conjugada $>12 \mathrm{mg} / \mathrm{dl}$ ) ocorre em $14 \%$ dos bebés amamentados e em $4 \%$ dos alimentados a leite artificial. Se tivermos em conta valores de bilirrubina superiores a $15 \mathrm{mg} / \mathrm{dl}$, a frequência é de $2 \%$ e $0,3 \%$ respectivamente. $^{16}$

Caso seja necessária fototerapia, em função do valor de bilirrubina, da idade da criança e da existência de patologia associada, não deverá existir separação entre a mãe e o bebé. A fototerapia induz um aumento das perdas insensíveis, pelo que é necessário fazer reforço hídrico oferecendo mais frequentemente a mama e/ou um suplemento no final, preferencialmente de 
leite materno extraído, que não só hidrata como nutre o RN. ${ }^{14,17}$

A amamentação deve ser iniciada precocemente tendo em vista uma mais rápida eliminação do mecónio. As mamadas frequentes e sem restrições $(>10 / 24 \mathrm{~h}$, mantendo mamadas nocturnas), aumentam o volume ingerido e o aporte calórico o que facilita a eliminação da bilirrubina.

\section{Icterícia do leite materno}

A icterícia associada à ingestão de leite materno tem uma incidência de 1:200 bebés amamentados. Surge mais tardiamente, entre o $4^{\circ}$ e o $7^{\circ}$ dia, com pico sérico de bilirrubina não conjugada na $2^{\mathrm{a}}$ a $3^{\mathrm{a}}$ semana, habitualmente inferior a $12 \mathrm{mg} / \mathrm{dl}$, decrescendo a partir daí, podendo no entanto manter-se durante 3 a 10 semanas com valores baixos. ${ }^{7}$

O leite de algumas destas mães contém glucoronidases (que desconjugam a bilirrubina e facilitam a sua reabsorção), inibidores da glucoroniltransferase e outras substâncias que competem com a bilirrubina na sua ligação à glucuroniltransferase..$^{7,15,16}$

Surge em bebés sem qualquer outra sintomatologia que apresentam uma óptima progressão ponderal, urina e fezes de coloração normal.

A fototerapia pode ser necessária. A interrupção do aleitamento com o intuito de diminuir a hiperbilirrubinémia pode causar problemas de lactação. A ausência de estímulo da mama (aquando da interrupção do aleitamento por $24 \mathrm{~h} / 48 \mathrm{~h}$ ) leva à diminuição da icterícia mas também à diminuição da produção de leite materno, além disso o uso da tetina obriga a uma sucção diferente da necessária na boa adaptação à mama, razões que podem estar na base dos problemas no restabelecimento da amamentação.

\section{Outras situações de hiperbilirrubinémia não conjugada no RN}

Existem outras situações de hiperbilirrubinémia não conjugada precoce a excluir: a doença hemolítica do $\mathrm{RN}$, incompatibilidade Rh ou ABO, esferocitose ou défice de G6PD. Outras situações com défice permanente do metabolismo da bilirrubina e aumento da fracção não conjugada, são: anemia hemolítica, hipotiroidismo, estenose hipertrófica do piloro, doença de Gilbert e síndrome de Crigler-Najjar.

\section{Kernicterus ou encefalopatia por bilirrubina}

O kernicterus é uma síndrome que resulta da deposição de bilirrubina não conjugada nos gânglios basais, córtex do hipocampo e no núcleo subtalâmico, provocando necrose celular. A patogénese do kernicterus é multifactorial e depende da interrelação dos níveis de bilirrubina, com a sua ligação à albumina, a passagem pela barreira hemato-encefálica e a susceptibilidade dos neurónios à lesão. O nível tóxico para determinado RN é imprevisível, mas o kernicterus é raro em RN saudáveis de termo na ausência de hemólise e com níveis inferiores a $25 \mathrm{mg} / \mathrm{dl}^{7,15}$

\section{Características das dejecções num RN amamentado}

Após as primeiras 24 horas de vida, o lactente amamentado frequentemente e em exclusivo, tem pelo menos 3 dejecções diárias, com eliminação precoce de mecónio e fezes amareladas a partir do $5^{\circ}$ dia.

Após este período inicial, o padrão de eliminação de fezes varia, de criança a criança, desde múltiplas dejecções diárias até dejecções com intervalos de vários dias, não estando indicado por rotina a estimulação da dejecção.

O atraso na eliminação de mecónio ou a existência de dejecções de cibalas podem corresponder à ingesta insuficiente de leite.

\section{Cólicas no lactente amamentado}

As cólicas são por definição contracções espasmódicas do músculo liso que causam dor e desconforto. No lactente, as cólicas surgem em paroxismos de irritabilidade, choro persistente, movimentos dos membros inferiores, repetindo-se habitualmente à mesma hora do dia. Surgem nos primeiros meses de vida e diminuem progressivamente após o $3^{\circ}$ mês de vida.

Num lactente amamentado com cólicas e antecedentes familiares de alergia às proteínas de leite de vaca propõe-se, durante duas semanas, a exclusão de leite de vaca da dieta materna. Em caso de melhoria sintomática, a exclusão de toda a proteína de vaca, pode ter maior impacto nas crianças com alergia às proteínas do leite de vaca. ${ }^{7}$ Muitos são os alimentos que são excluídos da alimentação da lactante sem que haja razão científica. Esta prática é muitas vezes responsável pelo empobrecimento do valor nutricional da dieta materna. Perante um alimento suspeito de causar alergia ou 
desconforto ao lactente, a mãe fará a prova de exclusão, durante duas semanas, seguida da reintrodução do alimento, e de acordo com a indicação médica, só se manterá a exclusão nos casos confirmados.

\section{CHORO}

O choro é uma das formas que o bebé tem de comunicar com quem dele cuida, o seu desagrado ou desconforto. A intensidade do choro para determinado bebé não é constante e habitualmente regista-se um pico às seis semanas, quando bebés saudáveis choram cerca de três horas por dia, decrescendo posteriormente para uma hora por dia ou menos aos três meses. ${ }^{8}$

Muitas vezes as mães associam o choro do seu bebé à fome. Compete aos profissionais de saúde reforçar perante as mães os sinais precoces de fome, para que possam responder da forma mais adequada ao bebé.

O bebé pode chorar quando colocado na mama se a transferência de leite não o satisfaz, se um fluxo de leite abundante lhe dificulta a coordenação da sucção e deglutição (reflexo de oxitocina materno muito exuberante), por candidíase oral ou por uma fractura da clavícula que passou desapercebida.

\section{CONCLUSÃO}

Promover a amamentação deve fazer parte integrante da intervenção na saúde de mães e bebés.

$\mathrm{Na}$ abordagem que fizemos de alguns dos problemas comuns neste período particular da lactação, não pretendemos ser exaustivos mas reforçar a noção de que importa equacionar a forma mais eficaz de intervirmos, fomentando o êxito da amamentação para a díade mãe/filho com benefício para a saúde de ambos.

\section{REFERÊNCIAS BIBLIOGRÁFICAS}

1. Academy of Breastfeeding Medicine Clinical Protocol Committee.ABM Clinical Protocol \#2 (2007 revision): guidelines for hospital discharge of the breastfeeding term newborn and mother: «the going home protocol». Breastfeed Med 2007 Sep; 2 (3):158-65.

2. The Academy of Breastfeeding Medicine. ABM Protocols - Protocol \#10: Breastfeeding the near-term infant (from 35 to 37 weeks gestation). Disponível em http://www.bfmed.org/Resources/Download. aspx?filename=Protocol_10.pdf [acedido em 25/06/200].

3. Papí AG. Problemas de los primeros dias. In:Asociación Española de Pediatria, editor. Manual de Lactancia Materna: de la teoria a la pratica. Madrid: Editorial Médica Panamericana; 2008. p. 183-6.

4. Wight N, Marinelli KA; Academy Of Breastfeeding Medicine Protocol Committee. ABM Clinical Protocol \#1: Guidelines for glucose monito- ring and treatment of hypoglycemia in breastfed neonates. Breastfeed Med 2006 Autumn; 1 (3):178-84.

5. Lorenzo JR, Pico MC, Bermúdez JM. Hipoglucemia Neonatal. In: Casanova M, Editor. Protocolos de Neonatologia, 2009. Disponível em: http://www.aeped.es/protocolos/neonatologia/18.pdf [acedido em 23/06/2009].

6. Kliegman RM, Behrman RE, Jenson HB, Stanton BF, editors. Nelson Textbook of Pediatrics. 18th ed. Philadelphia: Saunders; 2007. p. 665.

7. Lawrence RA, Lawrence RM. Breastfeeding: a guide for the medical profession. 6th ed. New York: Elsevier Mosby; 2005.

8. Feigelman S. The first year. In: Kliegman RM, Behrman RE, Jenson HB, Stanton BF, editors. Nelson Textbook of Pediatrics. 18th ed. Philadelphia: Saunders; 2007. p. 43-4.

9. Gonzalez C. Manual prático do aleitamento materno. Parede: Mama Mater; 2008. p. 70-1.

10. International Lactation Consultant Association. Clinical Guidelines for the Establishment of Exclusive Breastfeeding. Disponível em: http://www.ilca.org/files/resources/ClinicalGuidelines2005.pdf [acedido em 30/06/2009].

11. Papí AG. Problemas de los primeros dias. In:Asociación Española de Pediatria, editor. Manual de Lactancia Materna: de la teoria a la pratica. Madrid: Editorial Médica Panamericana; 2008. p. 192.

12. Greenbaum LA. Electrolyte and acid-base disorders. In: Kliegman RM, Behrman RE, Jenson HB, Stanton BF, editors. Nelson Textbook of Pediatrics. 18th ed. Philadelphia: Saunders; 2007. p. 274.

13. Papí AG. Problemas de los primeros dias. In:Asociación Española de Pediatria, editor. Manual de Lactancia Materna: de la teoria a la pratica. Madrid: Editorial Médica Panamericana; 2008. p. 180-2.

14. Renfrew MJ, Woolridge MW, McGill HR. Enabling women to breastfeed. London: The Stationary Office; 2000. p. 77.

15. Piazza AJ, Stoll BJ. Jaundice and hyperbilirubinemia in the newborn. In: Kliegman RM, Behrman RE, Jenson HB, Stanton BF, editors. Nelson Textbook of Pediatrics. 18th ed. Philadelphia: Saunders; 2007. p. 756$-8$.

16. Deshpande PG. Breast milk jaundice Disponível em: http://emedicine.medscape.com/article/973629-print [acedido em 20/06/2009].

17. American Academy of Pediatrics, Subcommittee on Hyperbilirubinemia. Management of hyperbilirubinemia in the newborn infant 35 or more weeks of gestation. Pediatrics 2004 Jul; 114 (1): 297-316.

18. Breastfeeding counseling - A training course - Director's Guide. Geneve: WHO / UNICEF; 1993. Disponível em:http://www.who.int/child_ adolescent_health/documents/pdfs/bc_directors_guide.pdf [acedido em 13/03/2008].

Conflitos de Interesse: não assinalados

\section{ENDEREÇO PARA CORRESPONDÊNCIA}

Cristina Gouveia

Rua Brites de Almeida, $n^{\circ} 6,3^{\circ}$ DTO.

8000-234 Faro

TIm: 968076006

E-mail: sinfantil@arsalgarve.min-saude.pt; tinagouveia@gmail.com 


\section{ABSTRACT}

The authors briefly address common situations of the infant that may have an impact on lactation (hypoglycemia and jaundice in infants, growth, dehydration, hypernatremia, among others). All interventions should be designed for the protection and support of breastfeeding.

Many situations can be prevented by early skin-to-skin contact after birth and early initiation of breastfeeding, followed by an unrestricted lactation in terms of duration, time between meals, or access to one or both breasts in each meal.

Mothers should also learn to recognize and offer the breast in response to early signs of hunger from the baby. Crying is a late sign.

Many situations in the first few days of life use to had their initial assessment in hospital after delivery, where women obtained the support they needed. Nowadays the desirable early discharges from hospital at 36-48 hours after birth shift these situations (like when the milk comes in) to primary care, underlining the importance of good communication between institutions for the effective support to the nursing mother.

Some common procedures, like supplementing feedings with artificial milk, are not designed for the promotion and maintenance of lactation and may influence its development.

Routinely weighting the baby without establishing a plan for effective weight progression can undermine mother's confidence.

Keywords: Lactation; Breastfeeding; Hypoglycaemia in Newborn; Common Problems. 